\title{
APPENDIX VII. ESTIMATED TEMPERATURE HISTORY IN THE LOWER PART OF HOLE 181 FROM CARBONIZATION MEASUREMENTS
}

\author{
John Grayson and Roger E. LaPlante, Amoco Production Company Research Center, Tulsa, Oklahoma
}

Two samples from Hole 181, Core 29, core catcher, were submitted to the Amoco Production Company Research Center for kerogen (organic matter) analysis. The principal interest was in the thermal history of these sediments which is reflected in the carbonization level of the kerogen. By comparing the carbonization level of the kerogen with that from Gulf Coast Tertiary sections something about past temperatures can be inferred (unpublished interpretation by Grayson and LaPlante).

Two stages of diagenesis of the residual organic matter were noted by Grayson-low carbonization level organic material and darker, more carbonized organic material. Translucency measurements of psilate, trilete spores (20 grains) indicate a range of $35 \%$ to $40 \%$ translucency with an average of $40.2 \%$. These translucency data indicate a carbonization level of approximately $70 \%$ to $73 \% \mathrm{C}$. This carbonization level is equivalent to Pleistocene sediments in the U. S. Gulf Coast province at approximately 8500 feet subsea and a $\log$ temperature of $155^{\circ} \mathrm{F}$. The abundant, darker (more carbonized) organic material noted by Grayson was in an advanced stage of diagenesis and probably was carbonized in older sediments and transported to the site and redeposited.

Elemental analysis by LaPlante indicated the following: $82.9 \% \mathrm{C} ; 3.8 \% \mathrm{H} ; 11.8 \% \mathrm{O} ; 1.5 \% \mathrm{~N}$. The percent carbon (carbonization level) probably reflects an averaging of two stages of diagenesis indicated above. This measured carbonization level, however, is equivalent to that of Oligocene sediments in the U.S. Gulf Coast province at approximately 17,000 feet with a log temperature of $280^{\circ} \mathrm{F}$. 